\title{
Production of Alumina-Rich Surface Film on AZ31 Magnesium Alloy by Anodizing with Co-Precipitation of Nano-Sized Alumina
}

\author{
S. A. Salman, R. Ichino and M. Okido \\ Department of Materials Science and Engineering, Graduate School of Engineering, \\ Nagoya University, Nagoya 464-8603, Japan
}

There are many techniques to deposit alumina film; most of these methods required special environment such as electrochemical deposition or complicated apparatus such as plasma spraying. In the present paper, anodizing of AZ31 in NaOH solution with co-precipitation of nano-size alumina particles was investigated to produce alumina-rich surface film on AZ31 magnesium alloy. The corrosion resistance was studied by potentiodynamic polarization technique; the corrosion resistance of AZ31 magnesium alloy was significantly improved by anodizing. [doi:10.2320/matertrans.MC2007111]

(Received November 6, 2007; Accepted February 8, 2008; Published April 25, 2008)

Keywords: AZ31 magnesium alloy, anodizing, alkaline solution, alumina particles

\section{Introduction}

The importance of magnesium alloys in various industries has increased significantly due to their high strength/weight ratio, high dimensional stability, good machining, and ability to be recycled. ${ }^{1,2)}$ However, surface treatments are necessary in order to protect against corrosion and to achieve the resistance necessary for many applications. Commonly applied surface treatment is the chemical conversion in which chromate bath is traditionally applied in spite of being not friendly to the environment. Chromium can be toxic for humans and difficult to be recyclable. ${ }^{3,4)}$ Alternative surface treatments are needed to produce a durable film onto $\mathrm{Mg}$ surface that would improve the corrosion resistance. In the previous works we investigated the effect of $\mathrm{Ca}(\mathrm{OH})_{2}$ and $\mathrm{Al}\left(\mathrm{NO}_{3}\right)_{3}$ additives to cerium-based solution on the morphology and corrosion resistance of the cerium conversion layer. $^{5)}$

In contrast to chemical conversion, anodizing can produce a relatively thick, dense, hard, adherent, abrasion-resistant and durable film to improve one or more surface properties, including chemical, mechanical, electrical or optical properties. ${ }^{6)}$ Anodizing of AZ31 magnesium alloy in alkaline solution with addition of $\mathrm{Na}_{2} \mathrm{~B}_{4} \mathrm{O}_{7}$ and $\mathrm{Na}_{2} \mathrm{SiO}_{3}$ enhances the anti-corrosion property and the surface morphology. ${ }^{7)} \mathrm{By}$ the addition of $\mathrm{NaAlO}_{2}$ into the base electrolyte, relatively coarse oxide coatings are obtained, however the number and size of micropores decrease with increasing the concentration of $\mathrm{NaAlO}_{2}{ }^{8)}$ The corrosion resistance reaches a maximum with respect to the aluminum content for magnesium-based alloys. ${ }^{9)}$

In the present paper, anodizing of $\mathrm{AZ} 31$ in $\mathrm{NaOH}$ solution with co-precipitation of nano-size alumina particles was investigated to produce Al-rich surface film on AZ31 magnesium alloy. This Al-rich surface could serve as starting point for further surface treatments.

\section{Experimental Procedure}

Commercially available AZ31 Mg alloy (3 mass\% Al, 1 mass $\% \mathrm{Zn}$ ) was used as the substrate. After the surface of the alloy was polished up to the \# 2000 emery paper followed by $0.05 \mu \mathrm{m}$ alumina powder, the specimens were carefully cleaned with water, rinsed with acetone and dried under air. The specimens were mounted using PTFE resin tape, leaving $1 \mathrm{~cm}^{2}$ surface area.

Electrochemical measurements were carried out using a conventional electrochemical cell equipped with three electrodes. Platinum, $\mathrm{Ag} / \mathrm{AgCl}$ sat. $\mathrm{KCl}$ and magnesium alloy specimen served as the counter, reference and working electrode, respectively. Measurements were taken at $298 \mathrm{~K}$ in $1 \mathrm{M} \mathrm{NaOH}$ alkaline solution with $10 \mathrm{~g} / \mathrm{l}$ alumina particles, the average size of $50 \mathrm{~nm}$ from Praxair Surface Technologies (Danbury, USA). To maintain a uniform distribution of the alumina particles in the solution, the bath solution was stirred by a magnetic stirrer. After the anodic films formed under constant potential electrolysis, the specimens were carefully rinsed using distilled water and dried under air before being introduced into the analyzer. The experiments were conducted in $0.2 \mathrm{dm}^{3}$ solution with constant agitation. The $\mathrm{Mg}$ alloys were anodized at constant potentials of $10 \mathrm{~V}$ for 30 minutes. The potentiodynamic polarization tests carried out using a Solartron 1285 Potentiostate with a scan rate of $1 \mathrm{mV} / \mathrm{s}$ in $17 \mathrm{mM} \mathrm{NaCl}$ and $0.1 \mathrm{M} \mathrm{Na}_{2} \mathrm{SO}_{4}$ solution at $298 \mathrm{~K}$. Platinum, $\mathrm{Ag} / \mathrm{AgCl}$ sat. $\mathrm{KCl}$ and magnesium alloy specimen served as the counter, reference and working electrode, respectively.

The surface morphology and microstructure of the oxide coatings were observed with a Hitachi S-800 scanning electron microscope (SEM) equipped with Kevex energydispersive X-ray spectroscopy (EDS) analysis tool and X-ray photoelectron spectroscope (XPS) operating with $\mathrm{Mg}-\mathrm{K} \alpha$ radiation as the excitation source.

\section{Results and Discussion}

The evolution of the current was investigated for anodizing at $10 \mathrm{~V}$ using $1 \mathrm{M} \mathrm{NaOH}$ with nano-size alumina particles (Fig. 1). Anodizing is controlled by the current density during the first period of anodizing, therefore; the magnesium alloy specimen is protected by a thin magnesium hydroxide film that offers little resistance to the current. A quick rise in 


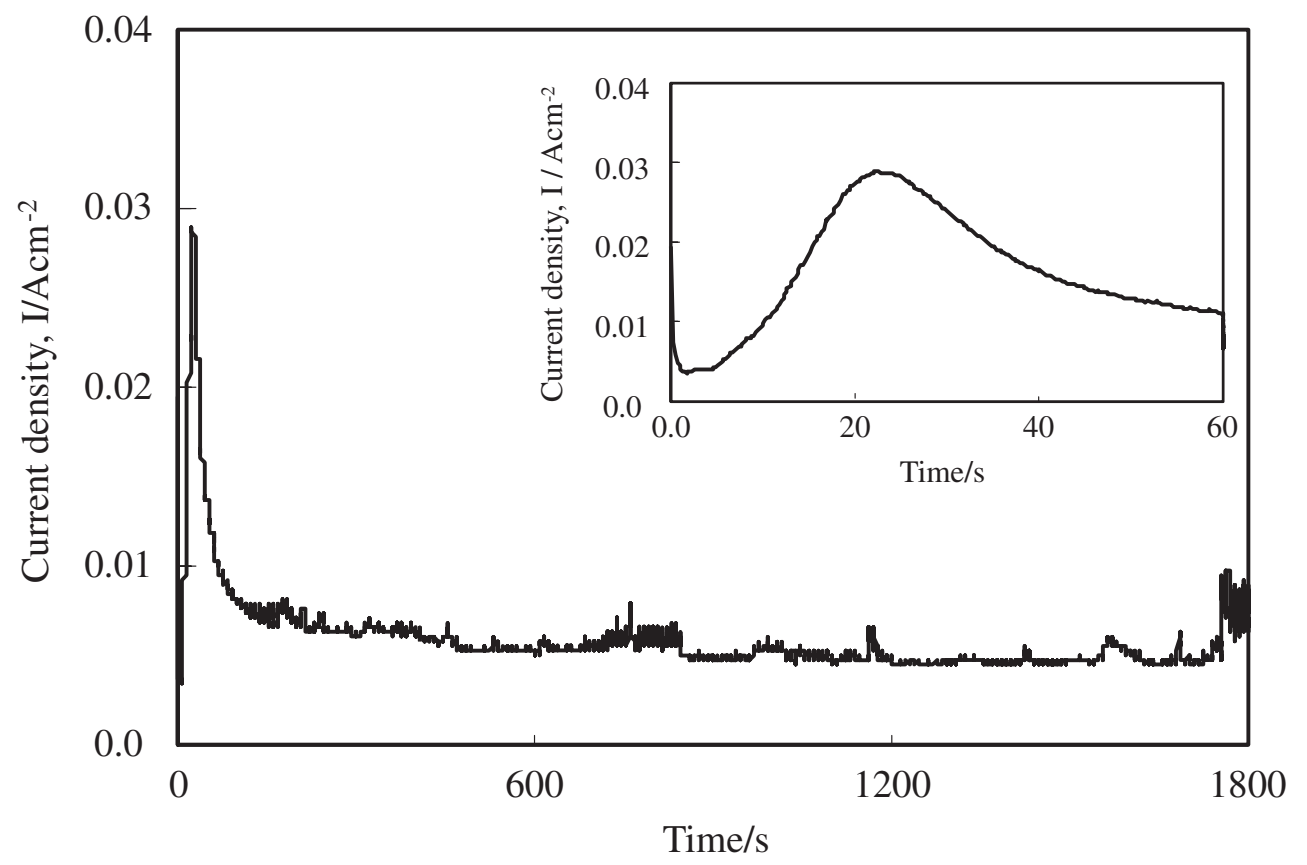

Fig. 1 Current density during anodizing at $10 \mathrm{~V}$ in $1 \mathrm{M} \mathrm{NaOH}+10 \mathrm{~g} / 1$ nano-size $\mathrm{Al}_{2} \mathrm{O}_{3}$ particles.

the current is produced due to the dissolution reaction of $\mathrm{Mg}$ and $\mathrm{Al}$ as shown in eqs. (1) and (2); the highest value of the current density was about $0.027 \mathrm{~A} / \mathrm{cm}^{2}$ after 23 second of the treatment time.

$$
\begin{aligned}
& \mathrm{Mg} \rightarrow \mathrm{Mg}^{2+}+2 \mathrm{e} \\
& \mathrm{Al} \rightarrow \mathrm{Al}^{3+}+3 \mathrm{e}
\end{aligned}
$$

$\mathrm{Mg}^{2+}$ accumulated on the surface and facilitates the precipitation of magnesium hydroxide (eq. 3) at $23 \mathrm{~s}$. treatment, then decreased in low rate until $400 \mathrm{~s}$.

After that the current density remains constant with time because of the stationary dissolution and film formation.

$$
\mathrm{Mg}^{2+}+2 \mathrm{OH}^{-} \rightarrow \mathrm{Mg}(\mathrm{OH})_{2}
$$

Once the $\mathrm{Al}^{3+}$ dissolved from the substrate, it immediately precipitates as aluminum hydroxides/oxides.

Point of zero charge of $\mathrm{Al}_{2} \mathrm{O}_{3}$ is about 9; a pH (13.5) in $1 \mathrm{M}$ $\mathrm{NaOH}$ solution is quite enough to produce stable negatively charged Alumina particles; which can be deposited on the anode during anodizing.

Figure 2 shows the SEM image of the anodized surface after the treatment in different durations. Figure 2(a) shows the surface after 1 min treatment; the surface was covered with a thin film of magnesium hydroxide and aluminum hydroxides and alumina particles. With increasing the time, the surface became coarser with large area of pores as shown in Figs. 2(b) and 2(c). After $30 \mathrm{~min}$ anodizing, the whole surface was covered with a compact film of precipitated alumina particles, these particles are binding together by magnesium hydroxide (Fig. 2(d)).

XPS results of the $\mathrm{Al} 2 \mathrm{p}$ and $\mathrm{O}$ 1s peaks of non-treated (solid line) and treated specimens (dashed line) were shown in Figs. 3(a), (b), respectively.

Figure 3(b) shows that the $\mathrm{O} 1 \mathrm{~s}$ peak of treated specimen was higher than that of non-treated one, suggesting the higher content of oxides and hydroxides on the surface of the treated specimen. In Fig. 3(a) the $\mathrm{Al} 2 \mathrm{p}$ of non-treated specimen was observed at $75 \mathrm{eV}$. In case of the treated specimen, however, this peak was increased, revealing the increase of the aluminum content in its surface by alumina particles and aluminum hydroxides/oxides.

The EDS results shown in Fig. 4 agreed with XPS data. Al, $\mathrm{Mg}$ and $\mathrm{O}$ were detected before anodizing Fig. 4(a). After anodizing in $1 \mathrm{M} \mathrm{NaOH}+10 \mathrm{~g} / 1$ nano-size particles of $\mathrm{Al}_{2} \mathrm{O}_{3}$, as shown in Fig. 4(b), we can clearly see that the peaks of aluminum and oxygen increased indicating $\mathrm{Al}$ enrichment at magnesium alloy surface by precipitation of alumina particles. Figure 4(c) shows that the white agglomerate is Al rich area compared with whole surface. These results support our suggestion that the alumina particles were precipitated, adhered to the surface and bended together by magnesium hydroxide. Figure 5 compared the anodic polarization curves of non-treated (solid line), and after $30 \mathrm{~min}$ anodizing in $1 \mathrm{M} \mathrm{NaOH}+10 \mathrm{~g} / 1$ nano-size $\mathrm{Al}_{2} \mathrm{O}_{3}$ particles (dashed line). Corrosion tests were performed in $17 \mathrm{mM}$ $\mathrm{NaCl}$ and $0.1 \mathrm{M} \mathrm{Na}_{2} \mathrm{SO}_{4}$ solution. The potential shifted in the nobel direction with anodizing treatment. The pitting potential as determined by the potentiodynamic scan has been shown to be related qualitatively to the resistance of a material to a loss of passivity by pit initiation. ${ }^{10)}$ The potential corresponding to anodic current density of $100 \mu \mathrm{Acm}^{-2}$ was considered as pitting potential, the pitting potential is increased by $170 \mathrm{mV}$ with anodizing, a notable passivity appears at anodic polarization curve.

\section{Conclusion}

The result shows that the surface of AZ31 magnesium alloy was enriched with alumina. The precipitation process directly proportional with time; after the 30 minutes treatment, the whole surface of the specimen was covered with alumina particles. 

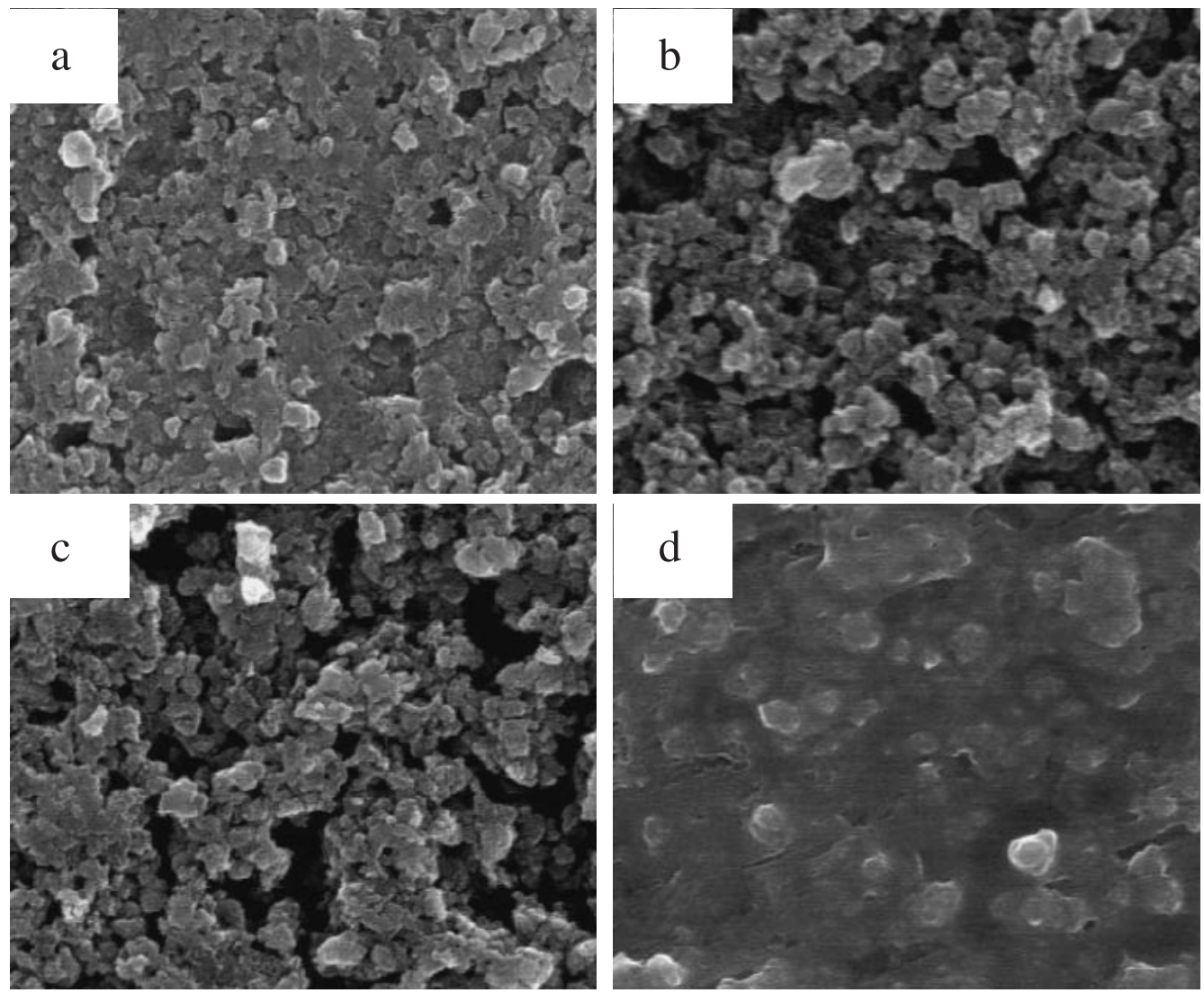

$2 \mu \mathrm{m}$

Fig. 2 Surface morphology for $\mathrm{AZ} 31 \mathrm{Mg}$ alloy after treatment in $1 \mathrm{M} \mathrm{NaOH}+10 \mathrm{~g} / 1$ nano-size $\mathrm{Al}_{2} \mathrm{O}_{3}$ particles; (a) $1 \mathrm{~min}$, (b) $3 \mathrm{~min}$, (c) $10 \mathrm{~min}$, and (d) $30 \mathrm{~min}$.
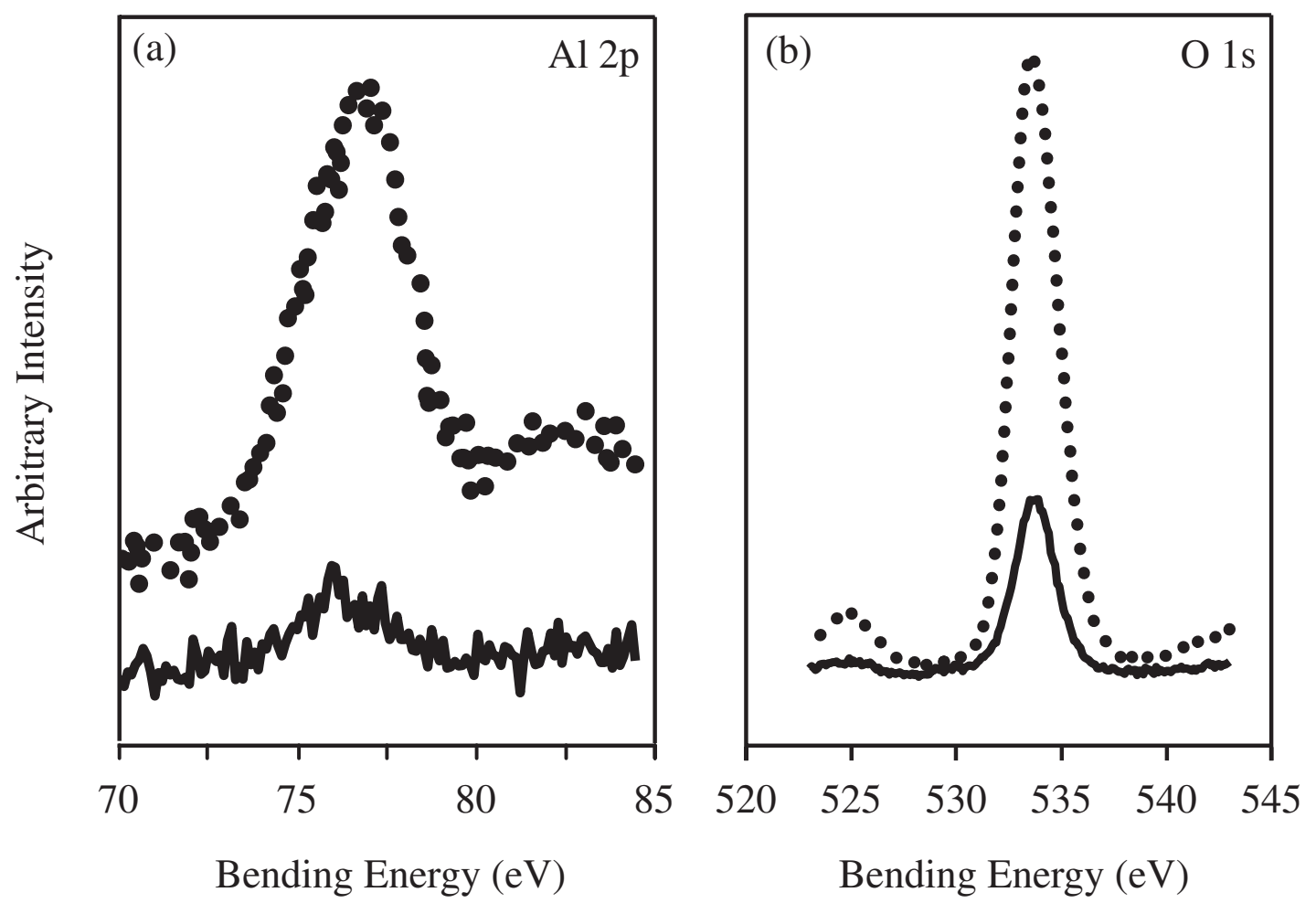

Fig. 3 XPS analysis for (a) $\mathrm{Al} 2 \mathrm{p}$ and (b) $\mathrm{O} 1 \mathrm{~s}$ for AZ31 Mg alloy before anodizing (solid line) and after anodizing in $1 \mathrm{M} \mathrm{NaOH}+10 \mathrm{~g} / 1$ nano-size $\mathrm{Al}_{2} \mathrm{O}_{3}$ particles (dashed line). 


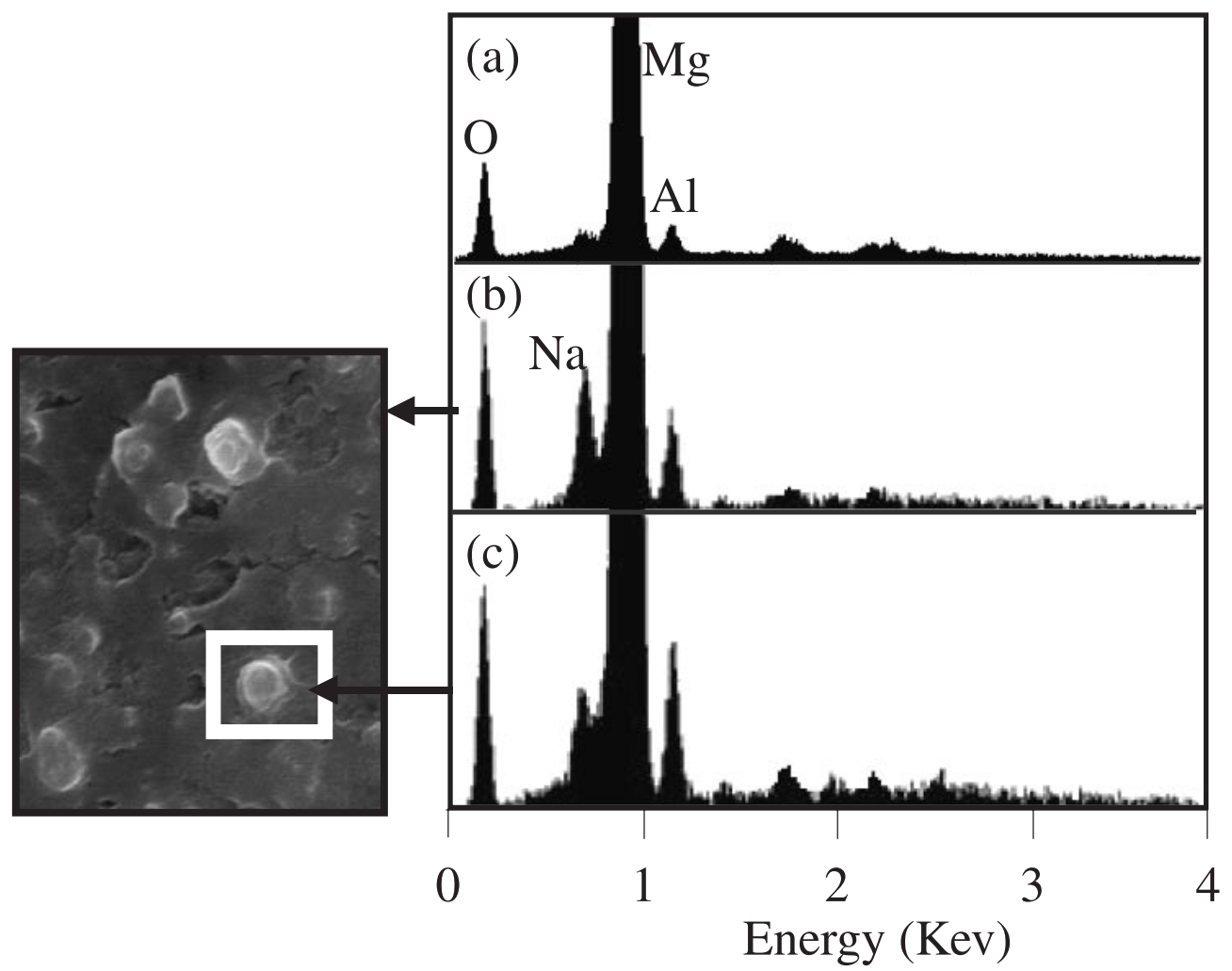

Fig. 4 EDS spectra for AZ31 Mg alloy; (a) before anodizing, (b) after anodizing in $1 \mathrm{M} \mathrm{NaOH}+10 \mathrm{~g} / 1$ nano-size $\mathrm{Al}_{2} \mathrm{O}_{3}$ particles, and (c) agglomerates area on the surface.

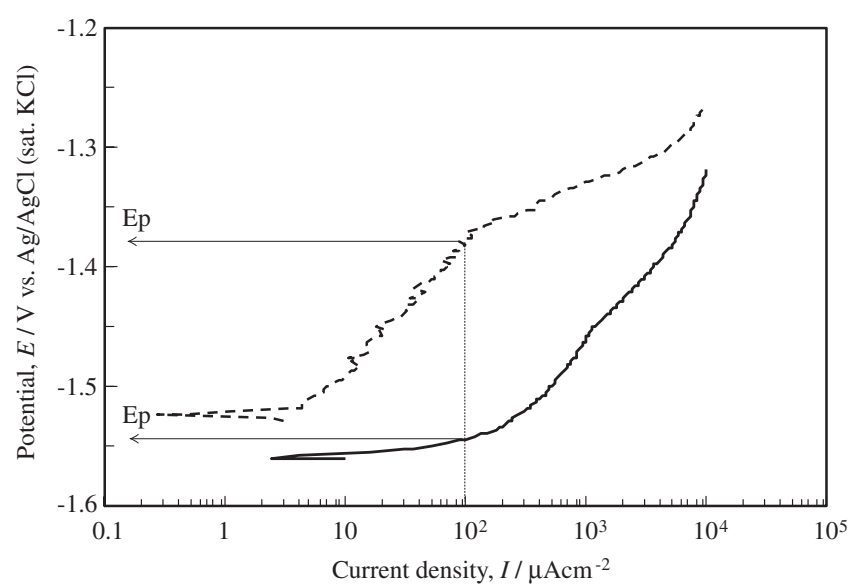

Fig. 5 The anodic polarization curves before anodizing (solid line), and after anodizing in $1 \mathrm{M} \mathrm{NaOH}+10 \mathrm{~g} / \mathrm{l}$ nano-size $\mathrm{Al}_{2} \mathrm{O}_{3}$ particles (dashed line).

The corrosion resistance of AZ31 magnesium alloy surface is noticeably improved after anodizing compared with non-treated specimen. The anodic polarization experiment shows that the pitting potential is increased by $170 \mathrm{mV}$ with anodizing.

\section{Acknowledgement}

The authors thank Dr. Kuroda and Mr. Kawade for their experimental assistance.

The financial assistance from The Ministry of Education, Science and Culture of Japan (Monbukagakusho) is gratefully acknowledged.

\section{REFERENCES}

1) E. F. Emley: Principle of Magnesium Technology; Pergamon Press: London, 1966.

2) Y. Mizutani, S. J. Kim, R. Ichino and M. Okido: Surface and Coatings Technology 169-170 (2003) 143-146.

3) S.-J. Kim, Y. Zhou, R. Ichino, M. Okido and S. Tanikawa: Metals and materials international 9-2 (2003) 207.

4) S.-J. Kim and M. Okido: Bull. Korean Chem. Soc. 24 (2003) 8975.

5) S. A. Salman, R. Ichino and M. Okido: Chem. Lett. 36-8 (2007) 1024.

6) Y. Zhang, C. Yan, F. Wang, H. Lou and C. Cao: Surface and Coatings Technology 161 (2002) 36-43.

7) S. A. Salman, Yu Xia, R. Ichino and M. Okido: 56th annual meeting of the international society of electrochemistry, (Busan, Korea, September 25-30, 2005), 4B-058-P, 720.

8) J. Lianga, B. Guoa, J. Tiana, H. Liua, J. Zhoua, W. Liua and T. Xua: Surface \& Coatings Technology 199 (2005) 121-126.

9) Magnesium Alloys and Technologies, ed. by K. U. Kainer, WiileyVCH, Germany, 2003, Chap. 14.pp. 229.

10) P. R. Roberge: Hand Book of Corrosion Engineering, McGraw-Hill, 2000 . 